\title{
GERMINAÇÃO E VIGOR DE SEMENTES DE MAMÃO (Carica papaya L.) cv. Golden SECADAS EM ALTAS TEMPERATURAS ${ }^{1}$
}

\author{
VINICIUS DE OLIVEIRA CARLESSO ${ }^{2}$, PEDRO AMORIM BERBERT ${ }^{3}$, ROBERTO FERREIRA DA SILVA ${ }^{4}$, \\ JOSÉ TARCÍSIO LIMA THIÉBAUT'; MARCIA TEREZINHA RAMOS DE OLIVEIRA ${ }^{6}$
}

\begin{abstract}
RESUMO - O presente estudo teve como objetivo avaliar os efeitos imediato e latente do emprego de altas temperaturas de secagem na qualidade fisiológica das sementes de mamão cv. Golden. Os testes de secagem por convecção, em camada delgada, foram realizados a 50 e $58^{\circ} \mathrm{C}$, empregandose fluxo de ar seco de $1,00 \mathrm{~kg} \mathrm{~s}^{-1} \mathrm{~m}^{-2}$; as sementes foram armazenadas a $15^{\circ} \mathrm{C}$, por 90 e 180 dias, em embalagens herméticas. A secagem a 50 e $58^{\circ} \mathrm{C}$ teve efeito imediato negativo sobre o vigor das sementes de mamão. Quanto ao efeito latente, apenas as sementes secadas a $58^{\circ} \mathrm{C}$ e armazenadas por 180 dias mantêm o mesmo vigor observado em sementes recém retiradas dos frutos. Em relação ao percentual de germinação, as sementes secadas a $50^{\circ} \mathrm{C}$ e avaliadas imediatamente depois da secagem são influenciadas negativamente pela secagem.
\end{abstract}

Termos para indexação: secagem de sementes, armazenamento, qualidade fisiológica

\section{GERMINATION AND VIGOUR OF HIGH-TEMPERATURE DRIED SEEDS OF GOLDEN PAPAYA (Carica papaya L.)}

\begin{abstract}
This study investigates the immediate and latent effects of high drying-air temperatures on the physiological quality of Golden papaya seeds. Thin-layer convective drying tests were conducted employing two levels of drying-air temperature, 50 and $58^{\circ} \mathrm{C}$, and a single level of dryairflow rate, $1.00 \mathrm{~kg} \mathrm{~s}^{-1} \mathrm{~m}^{-2}$. Upon removal from the dryer, seeds were hermetically stored at $15^{\circ} \mathrm{C}$ for 90 and 180 days. High drying-air temperatures had an immediate deleterious effect on seed vigour. Analysis of the latent effects revealed that best vigour results were obtained for seeds dried at $58^{\circ} \mathrm{C}$ and stored for 180 days at $15^{\circ} \mathrm{C}$. Germination percentage immediately after drying was reduced for seeds dried at $50^{\circ} \mathrm{C}$ only. Germination of the seeds submitted to other treatments was not affected by drying-air temperature or storage period, when compared to the values obtained for fresh seeds.
\end{abstract}

Index terms: seed drying, seed storage, physiological quality

${ }^{1}$ Submetido em 30/10/2008. Aceito para publicação, 13/04/2009.

${ }^{2}$ Eng. Agr., Doutorando do Programa de Pós-graduação em Produção Vegetal, Universidade Estadual do Norte Fluminense Darcy Ribeiro (UENF), CEP 28013-602 Campos dos Goytacazes, RJ. E-mail: carlesso@, uenf.br

${ }^{3}$ Eng. Agrícola, Ph.D., Professor Associado, Laboratório de Engenharia Agrícola (LEAG), Universidade Estadual do Norte Fluminense Darcy Ribeiro (UENF), CEP 28013-602 Campos dos Goytacazes, RJ. E-mail: pberbert@uenf.br

${ }^{4}$ Eng. Agr., Ph.D., Professor Titular, Laboratório de Fitotecnia (LFIT), Universidade Estadual do Norte Fluminense Darcy Ribeiro (UENF), CEP 28013-602 Campos dos Goytacazes, RJ. E-mail: roberto@uenf.br

${ }^{5}$ Eng. Agr., Professor Associado, LEAG/UENF. E-mail: jtt1512@uenf.br

${ }^{6}$ Tecnóloga em Horticultura, Doutoranda do Programa de Pós-graduação em Produção Vegetal, UENF. E-mail: maroli@uenf.br 


\section{INTRODUÇÃO}

O Brasil vem se destacando como o maior produtor mundial de mamão (Carica papaya L.), com aproximadamente 30.000 ha de área cultivada e com produção de 1,7 milhões de toneladas, em 2005; do total produzido, 2,5\% são destinados à exportação, principalmente para os Estados Unidos, principal mercado importador. México e Brasil são os dois únicos países com permissão para exportar para esse mercado, movimentando cerca de 98 milhões de dólares anuais (Agrianual, 2007).

Apesar de haver a tendência de se obter material propagativo por meios vegetativos, inclusive no Brasil, a propagação do mamoeiro para fins comerciais é feita basicamente por sementes. A propagação assexuada é bastante difundida na fruticultura, por permitir a obtenção de plantas com as características desejáveis das plantasmãe; no entanto, na cultura do mamoeiro esta prática não se difundiu em escala comercial. Atribui-se a isso, dentre outros fatores, o fato de se tratar de uma cultura de ciclo econômico relativamente curto (José e Marin, 1988).

A estimativa da utilização de sementes de mamão, no Brasil, é de aproximadamente $5.000 \mathrm{~kg}$ por ano, o que significa uma quantia superior a US\$ 4 milhões. Em função do custo elevado, vários produtores optam por produzir suas próprias sementes, reproduzindo em suas lavouras materiais de baixo padrão de qualidade genética, permanecendo no campo cultivares sem expressão econômica, com risco de disseminação de doenças de grande severidade para a cultura (Alves et al., 2003).

Os métodos mais empregados atualmente para secagem de sementes de mamão continuam sendo sua exposição às condições ambientais, à sombra ou sob pleno sol (Schmildt et al., 1993; Althoff e Carmona, 1999; Santos et al., 1999; Viggiano et al., 2000a; Martins et al., 2004 e 2005). Esses métodos, quando há prevalência de condições ambientais favoráveis, podem ser adequados para pequenas quantidades. No entanto, para um maior volume de sementes, e no caso da secagem à sombra, método com resultados geralmente superiores à secagem ao sol, a qualidade das sementes pode ser afetada quando predominam condições climáticas desfavoráveis durante o pré-processamento. Além disso, é maior a probabilidade de se obter lotes pouco homogêneos quanto à qualidade, quando a secagem é realizada sem que haja controle efetivo das variáveis envolvidas no processo. Quando a secagem não é realizada ao sol ou à sombra, empregam-se estufas com circulação forçada do ar, em que o único parâmetro controlado é a temperatura (Viggiano et al., 2000b; Aroucha et al., 2005; Tokuhisa et al., 2007).

Outro aspecto que deve ser considerado no estudo dos processos de secagem de sementes de mamão é o fato de raramente se conseguir reduzir, na secagem à sombra, $\mathrm{o}$ teor de água para níveis considerados adequados para um armazenamento seguro por longos períodos de tempo, ou seja, para valores entre 5 e $6 \%$. O potencial de secagem à sombra, nas regiões produtoras de mamão, permite a redução do teor de água de valores iniciais próximos a $45 \%$ para valores finais da ordem de $10 \%$, indicando a necessidade de complementação da secagem empregando-se métodos artificiais, como a secagem por convecção, utilizando ar ambiente ou aquecido.

Em geral, recomenda-se que a secagem de sementes seja realizada de tal forma que a temperatura delas não ultrapasse $40^{\circ} \mathrm{C}$, para que não haja redução acentuada de sua qualidade fisiológica. No entanto, a temperatura máxima às quais as sementes podem ser expostas, durante a secagem, depende do seu teor de água e do tempo de exposição a essa condição. Nellist (1978), citado por Brooker et al. (1992), menciona que sementes com teor de água de $18 \%$ poderiam ser secadas seguramente em leito fixo a $67^{\circ} \mathrm{C}$ e sementes a $26 \%$ só poderiam ser secadas, sob o mesmo procedimento, no máximo a $59^{\circ} \mathrm{C}$. Portanto, é possível que a secagem em altas temperaturas possa ser utilizada para aumentar a eficiência da secagem de sementes de mamão, reduzindo o manuseio e o tempo de secagem e mantendo a qualidade fisiológica.

Prado e Sartori (2000), no entanto, avaliaram o efeito imediato da temperatura e da velocidade do ar sobre a qualidade fisiológica de sementes de mamão. Verificaram que houve tendência de redução do vigor das sementes para as condições mais drásticas de secagem $\left(50^{\circ} \mathrm{C}\right.$ e $2,5 \mathrm{~m}$ $\mathrm{s}^{-1}$ ). Até o momento, este é o único trabalho publicado de investigação sobre a secagem de sementes de mamão em que as variáveis temperatura e velocidade do ar foram controladas e monitoradas durante todo o processo. Apesar de o efeito latente da secagem não ter sido avaliado, esse trabalho foi pioneiro na investigação do efeito imediato da secagem na qualidade fisiológica de sementes de mamão empregandose altas temperaturas. Sendo assim, considerando a importância da redução do tempo de manuseio e secagem no processamento de sementes de Carica papaya L., este trabalho teve como objetivo estudar os efeitos imediato e latente da secagem em altas temperaturas $\left(50\right.$ e $\left.58^{\circ} \mathrm{C}\right)$ sobre sua qualidade fisiológica.

\section{MATERIAL E MÉTODOS}

O presente trabalho foi realizado no Laboratório de Engenharia Agrícola (LEAG) da Universidade Estadual do Norte Fluminense Darcy Ribeiro (UENF), município de Campos dos Goytacazes - RJ. As sementes utilizadas 
foram obtidas de frutos de mamoeiro (Carica papaya L.) da cultivar Golden, fornecidos pela empresa Caliman Agrícola S/A, localizada no município de Linhares - ES. Os frutos foram colhidos no estádio de maturação 1, quando estavam amadurecendo e mudando de cor, apresentando os primeiros sinais amarelos, que não cobriam mais de $15 \%$ da casca. Os frutos foram então acondicionados em embalagens de papelão, colocados em caminhão com compartimento frigorificado e transportados para o laboratório. Após a recepção, os frutos foram armazenados em condições ambientais por 10 dias e a extração das sementes ocorreu quando estes se encontravam no estádio de maturação 5 , ou seja, maduros e com 75 a $100 \%$ da superfície da casca amarelada (CQH/CEAGESP, 2003).

A remoção das sementes foi feita seccionando-se os frutos ao meio com faca de aço inoxidável, no sentido longitudinal, sem permitir que a lâmina entrasse em contato com as sementes, evitando assim a ocorrência de danos mecânicos. Depois de extraídas dos frutos com o emprego de colheres, as sementes foram lavadas em água corrente sobre peneira de malha metálica, para retirada dos tecidos placentários e de parte da polpa, sendo, em seguida, submetidas ao processo de retirada da sarcotesta, que consistiu em friccioná-las manualmente, utilizando escova com cerdas de nylon, contra a malha da peneira, também sob jato de água. Para redução parcial do teor de água, as sementes foram expostas às condições do ambiente por cerca de $24 \mathrm{~h}$ e depois transferidas para estufa a $37^{\circ} \mathrm{C}$ por mais $12 \mathrm{~h}$.

O lote de sementes foi então dividido em três sublotes, para avaliação da qualidade fisiológica nas condições dos três tratamentos avaliados: sementes sem secagem e sementes secadas a 50 e $58^{\circ} \mathrm{C}$ em secador. O teor de água inicial das sementes foi determinado antes de se iniciar cada teste de secagem, obedecendo às recomendações propostas pelas Regras para Análise de Sementes (Brasil, 1992), a $130 \pm 1^{\circ} \mathrm{C}$ por $1 \mathrm{~h}$. Os testes de secagem das sementes foram realizados utilizando-se secador protótipo de camada delgada, fabricado pela Indústria e Comércio de Máquinas POLIDRYER Ltda., sediada em Viçosa $\mathrm{MG}$, com fluxo de ar ascendente, capaz de fornecer o ar de secagem em condições controladas de temperatura e vazão. Esse secador possui um ventilador centrífugo de $1,0 \mathrm{cv}$, um conjunto de resistências elétricas para aquecimento do ar, um inversor de freqüência para alterar e controlar a rotação do motor do ventilador, um controlador de temperatura com microprocessador, uma câmara plenum e um conjunto de esferas de vidro para diminuir a turbulência e uniformizar a velocidade do ar antes de sua entrada na câmara de secagem. Esta é composta por três bandejas circulares de diâmetro interno igual a $0,25 \mathrm{~m}$, com fundo perfurado em malha de aço inoxidável.

Amostras de sementes em equilíbrio térmico com o ar ambiente foram então colocadas na bandeja, cuja massa foi previamente determinada, sendo então espalhadas sobre o fundo perfurado, de maneira a formar uma camada fina com altura correspondente à espessura média das sementes. Em todos os testes, a redução do teor de água das sementes foi monitorada por gravimetria, pesando-se o conjunto bandejaamostra em intervalos regulares de cinco minutos na primeira meia hora e a cada $10 \mathrm{~min}$ até o fim da secagem, utilizandose balança digital SARTORIUS modelo BP 4100S, com grau de acurácia de $0,01 \mathrm{~g}$. O teor de água final foi novamente determinado imediatamente depois do processo de secagem das sementes.

O monitoramento da velocidade do ar de secagem foi realizado utilizando-se um anemômetro de pás rotativas AIRFLOW, modelo AV6 e a temperatura foi medida utilizando-se um termômetro de mercúrio com divisão da escala igual a $1^{\circ} \mathrm{C}$, localizado abaixo da câmara de secagem. As leituras de velocidade e temperatura do ar de secagem foram registradas antes de se retirar as bandejas em cada procedimento de pesagem. A temperatura e umidade relativa do ar ambiente foram medidas com um termohigrômetro digital HYGROMETER Series 485, fabricado pela DWYER INSTRUMENTS, INC. e registrados continuamente em termohigrógrafo SATO do tipo SIGMA II, modelo NS II-Q. A intenção deste monitoramento foi de avaliar as demais propriedades do ar de secagem, utilizando o programa computacional GRAPSI desenvolvido por Melo et al. (2004), para o cálculo das propriedades psicrométricas do ar.

Depois dos tratamentos de secagem, cada sublote foi novamente dividido em três porções, sendo a primeira utilizada para avaliar o efeito imediato da secagem na qualidade fisiológica das sementes e as outras duas, para avaliar o efeito latente da secagem ao final de períodos de 90 e 180 dias de armazenamento. As sementes foram acondicionadas em embalagens impermeáveis, ou seja, em frascos de vidro com tampa rosqueável e vedadas com Parafilm, e armazenadas a $15 \pm 1^{\circ} \mathrm{C}$ em câmara do tipo B.O.D.

A avaliação da qualidade fisiológica das sementes foi realizada mediante testes de vigor e germinação, de acordo com as Regras para Análise de Sementes (Brasil, 1992). Para estimar o vigor, realizou-se a contagem do número de plântulas normais fortes aos 14 dias do teste de germinação, 
contabilizando-se o número de plântulas com hipocótilo igual ou superior a $2,5 \mathrm{~cm}$. A estimativa da germinação foi realizada por meio da contagem do número de plântulas normais aos 28 dias da instalação do teste. Para melhor avaliação dos resultados, determinou-se também o número de plântulas normais fracas (plântulas pouco vigorosas, com hipocótilo inferior a 2,5cm), plântulas anormais (aquelas que apresentaram qualquer anormalidade e/ou ausência de alguma parte vegetativa: raiz, hipocótilo ou cotilédones) e sementes deterioradas (sementes que se apresentavam amolecidas e atacadas por fungos).

A análise estatística dos dados foi feita empregandose o método de Amostragem Simples ao Acaso (Cochran, 1977), em que cada semente representa uma unidade experimental. Os percentuais de germinação foram analisados e comparados por meio de intervalos de confiança, para o nível de significância de 5\%. As amostras foram dimensionadas considerando $\alpha=10 \%$ e $d=5 \%$ da média amostral.

\section{RESULTADOS E DISCUSSÃO}

As condições médias do ar ambiente e de secagem, as condições iniciais e finais das sementes, bem como o tempo de secagem durante os testes experimentais realizados a 50 e $58^{\circ} \mathrm{C}$ encontram-se na Tabela 1 . Observa-se que o incremento de $8^{\circ} \mathrm{C}$ na temperatura do ar proporcionou redução de $32 \%$ no tempo de secagem das sementes. O aumento da temperatura do ar úmido, mantendo-se a mesma razão da mistura $(0,019 \mathrm{~kg}$ de vapor por $\mathrm{kg}$ de ar seco), diminuiu a umidade relativa de 24 para $16 \%$ e aumentou a entalpia específica de 100 para $109 \mathrm{~kJ}$ por $\mathrm{kg}$ de ar seco (ASHRAE, 1992), aumentando, consequentemente o seu potencial de secagem (Silva et al., 2000).

TABELA 1. Condições médias do ar ambiente e de secagem, condições iniciais e finais das sementes e tempo de secagem a 50 e $58^{\circ} \mathrm{C}$

Temperatura de secagem $\left({ }^{\circ} \mathrm{C}\right)$

\section{Condições do ar ambiente:}

Temperatura, ${ }^{\circ} \mathrm{C}$

$33,8 \pm 0,5$

$34,1 \pm 0,2$

Razão da mistura, $\mathrm{kg} \mathrm{kg}^{-1}$

$0,019 \pm 0,001$

$0,019 \pm 0,001$

Condições do ar de secagem:

Temperatura, ${ }^{\circ} \mathrm{C}$

$50,2 \pm 1,1$

$57,5 \pm 0,6$

Velocidade, $\mathrm{m} \mathrm{s}^{-1}$

$0,9 \pm 0,01$

$0,9 \pm 0,01$

Vazão específica, $\mathrm{m}^{3} \min ^{-1} \mathrm{~m}^{-2}$

$53,8 \pm 0,4$

$54,7 \pm 0,5$

Fluxo de ar seco, $\mathrm{kg} \mathrm{s}^{-1} \mathrm{~m}^{-2}$

$1,00 \pm 0,01$

$1,01 \pm 0,01$

\section{Condições iniciais das sementes:}

Temperatura, ${ }^{\circ} \mathrm{C}$

33,8

34,1

Teor de água, \%

$52,9 \pm 1,3$

$52,9 \pm 1,3$

Condição final das sementes:

Teor de água, \%

$6,9 \pm 0,3$

$6,3 \pm 0,4$

Tempo de secagem:

Tempo, h 
Nas figuras mostrando os resultados da qualidade fisiológica obtidos pelo método da amostragem, a ocorrência de qualquer nível de superposição das barras horizontais que representam os intervalos de confiança para percentual de vigor e germinação, revela que não houve diferença significativa entre os tratamentos. Os valores de vigor para sementes recém-retiradas dos frutos e para aquelas secadas a $50^{\circ} \mathrm{C}$, imediatamente depois da secagem e nos dois períodos de armazenamento, e os respectivos intervalos de confiança, calculados pela contagem do número de plântulas normais com tamanho do hipocótilo $\geq 2,5 \mathrm{~cm}$, depois de 14 dias do início do teste de germinação, encontram-se na Figura 1A. Os valores correspondentes para sementes secadas a $58^{\circ} \mathrm{C}$ encontram-se na Figura 1B. Observa-se, nessas figuras, que as sementes apresentavam-se vigorosas antes de serem submetidas aos processos de secagem e armazenamento, com o vigor médio de $78 \%$. No entanto, é importante ressaltar que nas condições em que essas sementes encontravamse, com teor de água inicial superior a 50\%, considera-se inviável o seu armazenamento por períodos prolongados. Teores elevados de água, dependendo da temperatura de armazenamento, podem propiciar o desenvolvimento de fungos e o aumento do metabolismo das sementes, o que degradaria facilmente sua qualidade fisiológica. Nesse sentido, Oliveira e Trindade (2000) recomendam que sementes de mamão, antes de serem submetidas ao armazenamento, devem ter o seu teor de água reduzido para níveis adequados e tratadas com fungicidas.
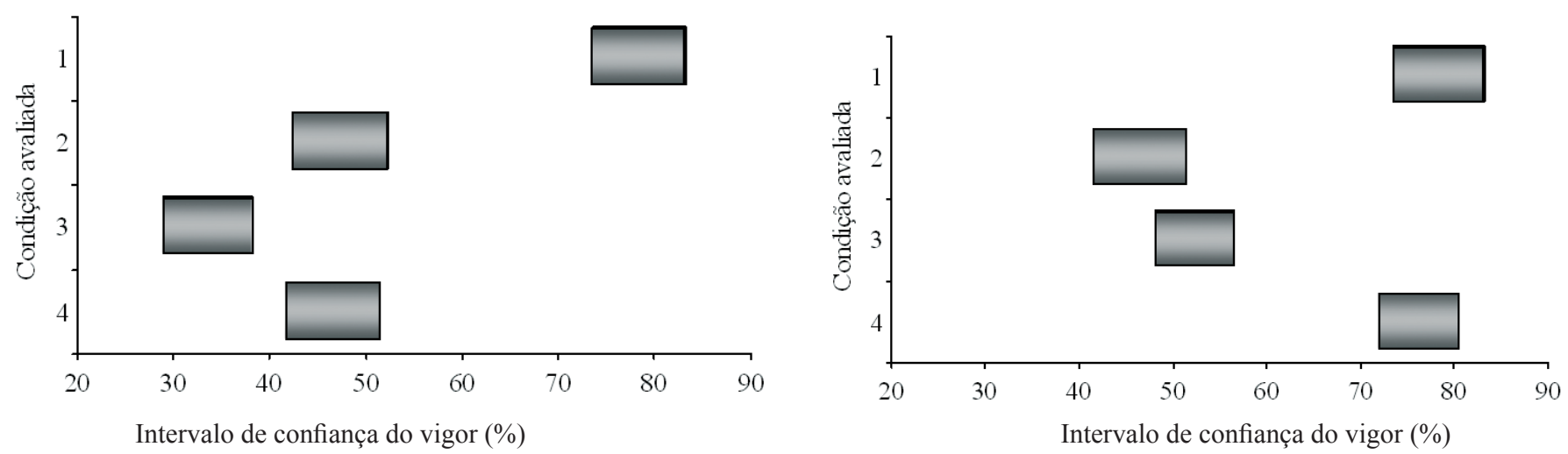

FIGURA 1. Intervalo de confiança, a 95\% de probabilidade, para o vigor de sementes de mamão sem secar e secadas a $50^{\circ} \mathrm{C}(\mathrm{A})$ e a $58^{\circ} \mathrm{C}(\mathrm{B})$, estimado por meio da contagem do número de plântulas normais fortes, com hipocótilo $\geq 2,5 \mathrm{~cm}$, aos 14 dias do teste de germinação, para as seguintes condições: sem secar (1); imediatamente depois da secagem (2); 90 dias de armazenamento (3); 180 dias de armazenamento (4).

Quanto ao efeito imediato da secagem, observou-se que as altas temperaturas influenciaram negativamente o vigor das sementes, reduzindo-o em aproximadamente 31 pontos percentuais em relação às sementes que não foram secadas (Figuras 1A e 1B). Viggiano et al. (2000a), mesmo empregando temperaturas ambientais de secagem à sombra, também observaram valores reduzidos de vigor em sementes de mamão no início do período de armazenamento, em avaliação realizada pela primeira contagem do teste de germinação; no entanto, é importante ressaltar que a secagem à sombra foi acompanhada de exposição das sementes ao sol por curtos períodos de tempo, o que certamente acarretou o aumento de sua temperatura, podendo ter contribuído para a redução do vigor. No entanto, na segunda avaliação, feita aos dois meses, os valores aumentaram consideravelmente, mantendo-se elevados até o oitavo mês, independentemente do teor de água, ambiente de armazenamento ou embalagem utilizada. Viggiano et al. (2000a) atribuíram este fato à ocorrência de dormência induzida pelo processo de secagem.

Em relação ao efeito latente, observou-se comportamento diferente entre as sementes secadas a 50 e $58^{\circ} \mathrm{C}$. Naquelas 
secadas a $50^{\circ} \mathrm{C}$ (Figura 1A), houve decréscimo acentuado do vigor entre zero e 90 dias de armazenamento, retornando posteriormente ao mesmo valor inicial ao fim de 180 dias. Para sementes secadas a $58^{\circ} \mathrm{C}$ (Figura 1B), não se observou redução no vigor entre zero e 90 dias de armazenamento; no entanto, ao fim de 180 dias de armazenamento, o vigor havia aumentado para valores superiores àqueles observados imediatamente depois da secagem. Esses resultados contradizem os encontrados por Martins et al. (2004), que verificaram que sementes de mamão do grupo Solo, cultivar Golden, secadas à sombra até teor de água de $10 \%$, apresentaram redução significativa na porcentagem de plântulas normais fortes depois de 180 dias de armazenamento.

Apresentam-se, na Figura 2, os intervalos de confiança referentes ao percentual de germinação das sementes de mamão, estimados por meio da contagem do número de plântulas normais aos 28 dias do teste de germinação, para temperaturas do ar de secagem de 50 e $58^{\circ} \mathrm{C}$. Na secagem a $50^{\circ} \mathrm{C}$ (Figura $2 \mathrm{~A}$ ) observou-se efeito imediato negativo da temperatura sobre o percentual de germinação das sementes, ou seja, a secagem induziu algum mecanismo de dormência ou produziu algum dano fisiológico às sementes. Se houve a indução de dormência, pode-se afirmar que esta não foi superada ao final de 90 ou 180 dias de armazenamento, uma vez que a germinação, ao final desses períodos, não diferiu do valor observado para sementes recém-retiradas dos frutos. Na secagem a $58^{\circ} \mathrm{C}$ (Figura 2B) observa-se que não houve efeito imediato ou latente da temperatura sobre a germinação das sementes, ou seja, não houve nem indução à dormência, nem danos fisiológicos causados às sementes; além disso, os resultados obtidos a $58^{\circ} \mathrm{C}$ foram, em geral, maiores quando comparados com os valores de germinação obtidos a $50^{\circ} \mathrm{C}$. Verifica-se, portanto, que o fator prevalente na obtenção de melhores resultados foi provavelmente o período de exposição das sementes a temperaturas elevadas e não propriamente a temperatura de secagem, para a faixa de temperaturas estudada. $\mathrm{Na}$ secagem a $58^{\circ} \mathrm{C}$ as sementes permaneceram em contato com o ar de secagem por $1,7 \mathrm{~h}$, ao passo que o período de exposição, na secagem a $50^{\circ} \mathrm{C}$, foi de 2,5h. De acordo com Nellist (1978), citado por Brooker et al. (1992), o valor máximo de temperatura considerado seguro para a secagem de sementes com teor de água de $30 \%$, para tempo de exposição superior a $1,0 \mathrm{~h}$, seria de $55^{\circ} \mathrm{C}$. No caso de sementes de mamão, verifica-se, portanto, que mesmo para sementes mais úmidas (53\%), o emprego de temperaturas ainda mais elevadas $\left(58^{\circ} \mathrm{C}\right)$, não foi capaz de produzir danos fisiológicos às sementes.
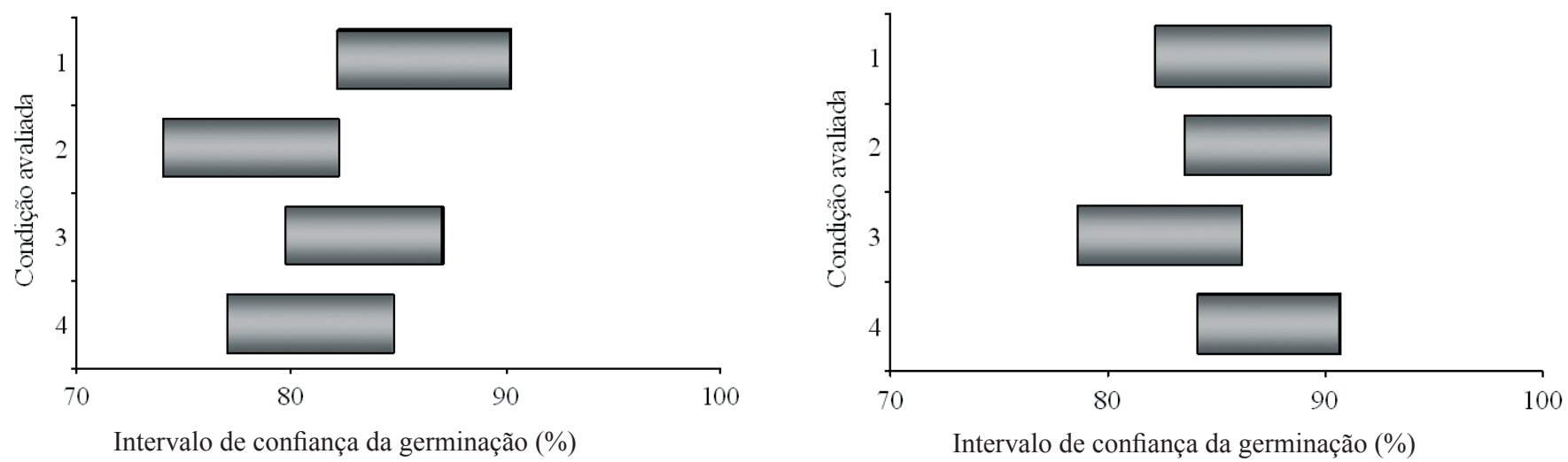

FIGURA 2. Intervalo de confiança, a $95 \%$ de probabilidade, para a germinação de sementes de mamão sem secar e secadas a $50^{\circ} \mathrm{C}(\mathrm{A})$ e a $58^{\circ} \mathrm{C}(\mathrm{B})$, estimado por meio da contagem do número de plântulas normais fortes aos 28 dias do teste de germinação, para as seguintes condições: sem secar (1); imediatamente depois da secagem (2); 90 dias de armazenamento (3); 180 dias de armazenamento (4).

Cavariani (1996), citado por Garcia et al. (2004), conjecturou que a causa primária do dano produzido por altas temperaturas em tecidos vegetais seria a desintegração das membranas celulares, possivelmente, por alterações nos lipídios que as constituem. Os danos fisiológicos provocados pela secagem poderiam se refletir, também, em alterações 
estruturais nas organelas, na redução do número de grãos de amido no eixo embrionário, na permeabilidade de membranas, e em aumento na lixiviação de eletrólitos e açúcares. No presente trabalho, não foram avaliadas as modificações ultraestruturais das células que compõem os tecidos das sementes de mamão, em função das condições estudadas, avaliação que poderia evidenciar a ocorrência de danos provocados pela utilização de altas temperaturas. No entanto, o teste de germinação pode ser considerado um método indireto para verificação da manifestação de danos térmicos em sementes. No presente caso, o número insignificante de plântulas anormais e o número reduzido de sementes duras ao final do teste de germinação, revelam que a temperatura de $58^{\circ} \mathrm{C}$ não foi suficiente para acarretar danos térmicos perceptíveis às sementes de mamão em nenhuma das condições avaliadas. Nem mesmo reduções consideráveis de vigor ao longo do armazenamento, outro tipo de manifestação de dano térmico preconizada por Nellist e Hughes (1973) e por Popinigis (1985), foram observadas no presente trabalho.

Os valores médios de germinação obtidos no presente trabalho, para ambas as temperaturas de secagem, ao final de 90 e de 180 dias de armazenamento a $15^{\circ} \mathrm{C}$ em embalagem impermeável, foram superiores a $80 \%$, o que, em termos práticos, podem ser considerados resultados satisfatórios. Althoff e Carmona (1999), ao avaliarem o efeito das condições de armazenamento na conservação de sementes de mamão com teor de água de $5 \%$, também obtiveram valores de germinação de cerca de $80 \%$, ao final de 180 dias de armazenamento, em condições ambientes e a $5^{\circ} \mathrm{C}$, independentemente do tipo de embalagem utilizado, permeável (papel Kraft) ou impermeável (lata).

\section{CONCLUSÕES}

A secagem a 50 e $58^{\circ} \mathrm{C}$ tem efeito imediato negativo sobre o vigor das sementes de mamão. Quanto ao efeito latente, sementes secadas a $58^{\circ} \mathrm{C}$ e armazenadas por 180 dias mantêm o mesmo vigor observado em sementes recémretiradas dos frutos.

Em relação ao percentual de germinação, apenas as sementes secadas a $50^{\circ} \mathrm{C}$ e avaliadas imediatamente após a secagem são influenciadas negativamente pela secagem.

\section{AGRADECIMENTOS}

Os autores agradecem o apoio técnico e financeiro oferecido pelas seguintes instituições: CALIMAN AGRÍCOLA S/A, CAPES, CNPq, FAPERJ, FINEP e
International Foundation for Science (IFS).

\section{REFERÊNCIAS}

AGRIANUAL: anuário da agricultura brasileira. São Paulo: FNP Consultoria e Comércio, 2007. 520p.

ALTHOFF, M.A.; CARMONA, R. Conservação de sementes de mamão (Carica papaya L. Caricaceae). Revista Brasileira de Sementes, v.21, n.1, p.151-156, 1999.

ALVES, F.L.; PACOVA, B.E.V.; GALVAES, P.A.O. Seleção de plantas matrizes de mamão, grupo Solo, para produção de sementes. In: MARTINES, D.S.; COSTA, A.F.S. (Ed.). A cultura do mamoeiro: tecnologias de produção. Vitória: Incaper, 2003. p.103-114.

AROUCHA, E.M.M.; SILVA, R.F.; OLIVEIRA, J.G.; VIANA, A.P.; GONZAGA, M.P. Época de colheita e período de repouso dos frutos de mamão (Carica papaya L.) cv. Golden na qualidade fisiológica das sementes. Ciência Rural, v. 35, n.3, p.537-543, 2005.

ASHRAE. Psychrometric chart No. 3 (SI). High temperature $\left(10\right.$ to $\left.120{ }^{\circ} \mathrm{C}\right)$ - Sea level. Atlanta: American Society of Heating, Refrigerating, and Air-Conditioning Engineers, 1992. 1p.

BRASIL. Ministério da Agricultura e Reforma Agrária. Regras para análise de sementes. Brasília, DF: SNDA/ DNDV/CLAV, 1992. 365p.

BROOKER, D.B.; BAKKER-ARKEMA, F.W.; HALL, C.W. Drying and storage of grains and oilseeds. New York: Van Nostrand Reinhold, 1992. 451p.

CQH/CEAGESP. Programa brasileiro para a modernização da horticultura. Normas de classificação do mamão (Carica papaya L.). Centro de Qualidade em Horticultura (CQH) / Companhia de Entrepostos e Armazéns Gerais de São Paulo (CEAGESP). São Paulo: CQH 2003. 6p. (Documento 25).

COCHRAN, W.G. Sampling techniques. New York: John Wiley \& Sons, Inc., 1977. 448p.

GARCIA, D.C.; BARROS, A.C.S.A.; PESKE, S.T.; MENEZES, N.L. A secagem de sementes. Ciência Rural, v.34, n.2, p.603-608, 2004.

JOSÉ, A.S.; MARIN, S.L.D. Propagação do mamoeiro. In: RUGGIERO, C. (Ed.). Mamão. Jaboticabal: FCAV/ UNESP, 1988. p.177-194. 
MARTINS, G.M.; SILVA, R.F.; ARAÚJO, E.F.; VIEIRA, H.D.; VIANA, A.P. Influência do tamanho do fruto, do peso específico e do período de armazenamento na qualidade fisiológica de sementes de mamão cv. Golden. Revista Brasileira de Armazenamento, v. 29, n.2, p.98-103, 2004.

MARTINS, G.M.; SILVA, R.F.; ARAÚJO, E.F.; PEREIRA, M.G.; VIEIRA, H.D.; VIANA, A.P. Influência do tipo de fruto, peso específico e do período de armazenamento na qualidade fisiológica de sementes de mamão do grupo Formosa. Revista Brasileira de Sementes, v.27, n.2, p.1217, 2005.

MELO, E.C.; LOPES, D.C.; CORRÊA, P.C. GRAPSI Programa computacional para o cálculo das propriedades psicrométricas do ar. Engenharia na Agricultura, v.12, n.2, p.145-154, 2004.

NELLIST, M.E.; HUGHES, M. Physical and biological processes in the drying of seed. Seed Science and Technology, v.1, n.1, p.613-643, 1973.

OLIVEIRA, J.R.P.; TRINDADE, A.V. Propagação e formação de pomar. In: TRINDADE, A.V. (Ed.). Mamão produção: aspectos técnicos. Brasília, DF: Embrapa, 2000. p.20-25.

POPINIGIS, F. Fisiologia da semente. Brasília: AGIPLAN, 1985. 289p.

PRADO, M.M.; SARTORI, D.J.M. Avaliação da secagem convectiva de sementes de papaya com e sem mucilagem. In: CONGRESSO BRASILEIRO DE ENGENHARIA QUÍMICA, 13, 2000, Águas de São Pedro. Anais... Águas de São Pedro: Sonopress Rimo LTDA, 2000. v.1, p.5480154810 .

SANTOS, R.C.A.; AMPAIO, L.S.V.; COSTA, J.A. Condição ambiental, teor de água e embalagem na viabilidade e no vigor de sementes de mamão. Revista Brasileira de Sementes, v.21, n.2, p.194-202, 1999.

SCHMILDT, E.R.; FRONZA, V.; DIAS, J.L.S.; UNÊDA, S.H.; ALVARENGA, E.M. Comparação de métodos físicos de remoção da sarcotesta e de métodos de secagem de sementes de mamoeiro (Carica papaya L.). Revista Brasileira de Sementes, v. 15, n. 2, p. 147-151, 1993.

SILVA, J.S.; AFONSO, A.D.L.; DONZELLES, S.M.L. Secagem e secadores. In: SILVA, J.S. (Ed.). Secagem e armazenagem de produtos agrícolas. Viçosa: Aprenda Fácil, 2000. p.107-138.

TOKUHISA, D.; DIAS, D.C.F.S.; ALVARENGA, E.M.; DIAS, L.A.S.; MARIN, S.L.D. Tratamentos para superação da dormência em sementes de mamão. Revista Brasileira de Sementes, v.29, n.1, p.131-139, 2007.

VIGGIANO, J.R.; VIEIRA, H.D.; SILVA, R.F.; ARAÚJO, E.F.; VIANA, A.P. Conservação de sementes de mamão (Carica papaya L.) em função do grau de umidade, tipo de embalagem e ambiente de armazenamento. Revista Brasileira de Sementes, v.22, n.2, p.279-287, 2000a.

VIGGIANO, J.R.; SILVA, R.F.; VIEIRA, H.D. Ocorrência de dormência em sementes de mamão (Carica papaya L.). Sementes Online, n.1, p.06-10, 2000 b. 